\title{
Covid-19 e os impactos na produção de festivais de cinema brasileiros: estratégias cotidianas para migração online ${ }^{1}$
}

Eveline Stella de Araujo ${ }^{2}$

Sabrina Demozzi ${ }^{3}$

Resumo

1 Texto com base no trabalho final apresentado na disciplina Cultura Digital e Sociedade Contemporânea, ministrada pela Prof ${ }^{a}$ Dr $^{\mathrm{a}}$ Myrian Regina Del Vecchio Lima, no âmbito do PPCOM-UFPR, em outubro de 2020, de modo remoto em função da pandemia de Covid-19.

2 Doutora em Saúde Pública (USP) e Doutoranda em Comunicação pelo PPGCOM-UFPR, foi bolsista Capes-DS de agosto a dezembro de 2019. Pesquisadora no Grupo de Antropologia Visual (Gravi-USP), Centro de Estudos de Religiosidade e Cultura Negra (CERNe-USP) e Núcleo de Estudos em Ficção Seriada (Nefics-UFPR). Diretora do Cine Tornado Festival. Pósdoc na Cátedra Alfredo Bosi de Educação Básica, IEA-USP.

Email: evelinetornado@gmail.com

${ }^{3}$ Jornalista e Mestre em História pelo PRPPG-UFPR.

Email: sabrinademozzi@gmail.com 
No Brasil, as atividades culturais migraram para o sistema online em função da pandemia de coronavírus a partir de 2020. Desse modo, busca-se identificar as estratégias de virtualização das exibições cinematográficas no contexto dos festivais produzidos por brasileiros, a partir de pesquisa exploratória com aplicação de questionário e de consulta de dados estatísticos e georreferenciados, disponíveis na Internet, sobre o contexto da indústria cinematográfica referente ao Brasil. Dentre os achados, foi identificada a preocupação com a experiência do consumo; com a adequação da linguagem e dos processos de trabalho à nova realidade; bem como a adaptação dos contratos de direitos autorais. Há possibilidade de manter atividades no modo híbrido no cenário pós-pandemia para ampliar a presença social e digital da cultura. Conclui-se que a virtualização dos festivais desvelou a capacidade criativa da classe artística no contexto de crise para mobilização e engajamento social e digital com o público de cinema e tornou o circuito de festivais de cinema mais acessível em todo o território brasileiro.

Palavras-chave: Exibição de filmes; Cultura Digital; Pandemia de Covid-19; Cinema.

\section{Abstract}

In Brazil, cultural activities migrated to the online system due to the coronavirus pandemic. Therefore, we seek to identify the virtualization strategies of cinema programs in the context of festivals produced by Brazilians, based on exploratory research with the application of a questionnaire and the consultation of statistical and georeferenced data available on the Internet in the context of the film industry. Among the findings, we identify the concern with the consumption experience; with the adequacy of language and work processes to the new reality; as well as the adaptation of copyright contracts. There is a possibility of maintaining activities in hybrid mode in the post-pandemic scenario to increase the social and digital presence of culture. We concluded that the virtualization of festivals unveiled the creative capacity of the artistic class in the context of crisis for mobilization and social and digital engagement with the cinema audience.

Keywords: Film exhibition; Digital Culture; Pandemic; Cinema.

\section{INTRODUÇÃO}


"Assim como a crise de 1929 ou a Segunda Guerra fizeram, a Covid-19 marcará uma nova era do cinema. A reorganização de forças entre os players e a redefinição das formas de consumir, ver e sentir - transformações que estavam em curso, diga-se - passaram a ser involuntariamente postas em prática" (SOUSA, 2020)

A afirmação de Ana Paula Sousa extraída do texto "Coronavírus vai marcar o fim de uma era no cinema", publicado em $1 \stackrel{0}{ }$ de maio de 2020, na Folha de S. Paulo não foi a primeira e nem será a última análise a respeito das transformações ocorridas no mercado audiovisual em decorrência da pandemia do Covid-19. Selecionamos esse trecho da matéria porque dialoga com a proposta deste artigo em identificar as estratégias adotadas pelos setores culturais frente as contingências impostas pela pandemia no contexto brasileiro, impactado em seu cotidiano por questionamentos políticos, sociais e estéticos de restrição da liberdade. Partimos, para isso, do conceito de cultura proposto por WILLIAMS ${ }^{4}$ (2011), nos Estudos Culturais de tradição angloamericana, para o qual há uma relação intrínseca entre cultura, poder e economia, considerando as relações sociais e os aspectos históricos. Porém, para aplicá-lo ao contexto brasileiro, articulamos esse conceito às pesquisas provenientes da América Latina no mesmo campo, que ampliam a discussão sobre a cultura, propondo um olhar descentralizador do eurocentrismo na modernidade ocidental, com consequente visibilidade dos movimentos sociais periféricos (RESTEPRO, 2015). No campo da cibercultura, elemento mobilizador da migração para o online, nos apropriamos da compreensão de $\operatorname{NAYAR}^{5}$ (2010) ao analisar a cultura digital integrando-a aos processos políticos, históricos e sociais para compreendê-la no contexto cotidiano marcado por tensões, dinâmicas e conflito. Este autor defende que existem várias ciberculturas num espaço de disputa entre discursos e representações, referindo-se ao processo de controle do espaço cibernético por empresas conglomeradas norte-americanas e às resistências e práticas locais de existir no ciberespaço.

Fechando essa tríade conceitual necessária para o artigo, entendemos os festivais de cinema com uma complexa forma de interação cultural. Os festivais podem ser pensados como moduladores de hábitos de consumo ou como elementos de

\footnotetext{
${ }^{4} \mathrm{O}$ conceito de Cultura em Raymond Williams foi apresentado de forma simples e didática por AZEVEDO (2017) em língua portuguesa. E o artigo de RESTREPO (2015) faz uma análise do surgimento e da tensão no estabelecimento do campo dos Estudos Culturais na América-Latina.

${ }^{5}$ Esse autor é apresentado no Brasil por MARTINO (2014), na obra Teoria das Mídias Digitais, tendo grande influência na produção acadêmica pelo grande esforço de sistematização realizado no campo da comunicação digital.
} 
convergência cultural, inseridos na circulação e exibição das obras cinematográficas. Os festivais são uma espécie de contrapartida à ocupação das salas de cinema comerciais pela indústria cultural, que pensa o filme como entretenimento, principalmente a indústria norte-americana (ROCHA; VACCARINI, 2015; DENNISON, 2019). Nesse sentido, os festivais de cinema, especialmente no Brasil, consolidam-se por seu perfil artístico e experimental referente às temáticas, narrativas sociais e aos processos criativos tecnológicos. Estão em alguns casos associados ao artivismo (ARAUJO, 2017), quando a arte manifesta as tensões políticas e econômicas que constrangem a sua expressão. Os diversos festivais LGBTI+, festivais de Cinema Indígena, festivais de filmes sobre refugiados e imigrantes - como o promovido pelo GRIST (Grupo de Refugiados e Imigrantes Sem Teto), que ocorreu em 2017, no Centro das Culturas Negras, no bairro do Jabaquara, São Paulo, capital - são alguns exemplos que apontam para a necessidade de um olhar atento para as narrativas do próprio festival enquanto um evento cultural, para além das narrativas dos filmes acolhidos pela curadoria na programação. Nesse sentido, a associação de obras inéditas de diretores consagrados com obras de iniciantes não só traduz os festivais como espaços democráticos de produção artística, que acolhe tanto curtas quanto longas-metragens, mas como um espaço de fala de si, de construção de si enquanto sujeito que deseja e almeja ser representado de forma satisfatória e não estereotipada. Esse caráter implica em inovações estéticas e narrativas a ser acompanhadas pelo mercado audiovisual (CIRINO; CANUTO, 2021). Os festivais têm um poderoso papel de protagonismo nos processos de transformação simbólica das sociedades, por seu aspecto midiatizado e de espetáculo (MATTOS, 2013). A esse aspecto acrescentamos os espaços de debate e participação do público em sessões que permitem trocas com os diretores, a votação nos filmes, ou a participação em masterclasses sobre o método de realização do filme, estimulando uma ambiência de protagonismo da audiência, dos curadores, dos realizadores de filmes e das distribuidoras. Esses espaços são janelas essenciais para a conexão entre eles. Leal e Mattos (2007), referindo-se à criação da carta do Fórum Festivais escrita em 2000, analisam que no Brasil, a partir dessa iniciativa, os festivais começaram a ser vistos por três dimensões: espaços de visibilidade (agentes de identidade); excelência nos projetos (muitas vezes relacionados com o turismo regional), e viabilização de modelos de negócios culturais (para além de patrocínio ou editais públicos), caracterizando os festivais como eventos culturais com calendário próprio. Já a pesquisadora Dennison (2019) faz um balanço da cultura cinematográfica brasileira dos últimos 20 anos apontando para a ampliação da visibilidade das minorias e grupos subalternizados, para os formatos criativos dos festivais brasileiros e para a inserção no 
cenário internacional de festivais. Entretanto, a noção de curadoria dos festivais de cinema (GARRETT, 2020) como expressão de narrativas sociais ampliadas calcadas em práticas sociais, nos termos propostos por Araujo e Gallo (2017), é o ponto de inflexão, pois atua não só no acesso à cultura - previsto na Constituição Federal do Brasil de 1988, em seu artigo 215, como potência para a formação de público crítico, visto a característica de vanguarda e inovação -, mas, principalmente, como um espaço de resistência social, de construção da apropriação da linguagem e de políticas de visibilidade.

Para tratar especialmente do segmento dos festivais de cinema realizados no formato digital com transmissão online, por essa perspectiva, é preciso compreender algumas condições e características desse setor cultural, a sua importância e o papel dos festivais no contexto da pandemia, onde disputam espaço com programações on demand ofertadas por streamings de grandes corporações. Ainda que o formato de festival de cinema online ocorra desde $1991 \mathrm{em}$ pequena escala e fundamentalmente com curtas-metragens, como o Festival do Minuto, por exemplo, não era até então a realidade da maioria dos festivais realizados no Brasil. O desafio está em compreender como, na cultura digital a partir dessa migração para o online, possa ocorrer a formação de comunidades virtuais (RECUERO, 2001) para engajamento imediato; quais os desafios para elaborar novas relações cotidianas no mundo das artes com a sociedade em geral no ambiente online, marcado principalmente pela ubiquidade e fragmentação da atenção (SANTAELLA, 2010; ARAUJO; GALLO, 2017). Compreender a complexa conjuntura cultural contemporânea implica perceber suas expressões multiculturais, a fluidez dos processos comunicacionais em culturas híbridas, como propõe CANCLINI (1998) - termo incorporado por SANTAELLA (2010) ao contexto da convergência midiática -, projetando esse aspecto também na cultura digital. Entretanto, devemos compreender que os processos de disputa comunicacionais levam a processos estruturantes de midiatização (LEMOS, 2020), eclipsados no termo 'híbrido' quando associado ao ambiente digital.

As relações no mundo dos festivais de cinema passam a ser compreendidas pela necessidade de criar comunidades virtuais integrada em uma cultura digital mais ampla. MALDONADO (2008) afirma que:

[a] transformação tecnocultural que a invenção e o funcionamento do tempo/espaço digital têm tornado possível, suscitou, também, um desenvolvimento da cultura das redes, dado que as conexões entre nós e sujeitos apresentam-se factíveis e em condições de 
intensificação, intercâmbio, cooperação e fluxo mais eficientes e dinâmicos que nos formatos atômicos" (2008: 4).

A realidade da pandemia impactou sobremaneira os modos de fazer e de organizar as ações dos eventos culturais - que antes tinham uma comunicação digital mais pontual, mais associada com a divulgação, pois em sua maioria os eventos eram presenciais - como shows musicais, peças teatrais e festivais de cinema. Diante da contingência e avaliando os prós e os contras, muitos festivais optaram pela realização em sistema virtual e entraram na disputa comunicacional na cultura digital, o mesmo ocorrendo com alguns cineclubes. Mencionamos esse aspecto pois essa relação entre promotores de festivais de cinema e cineclubistas é fundamental para o engajamento de público (NOLASCO, 2020). Para os festivais que possuem sistema de votação de público, é essencial um público crítico, para que a premiação seja feita motivada pela qualidade das obras e não só por engajamento dos diretores em redes sociais, visto que a atuação das pessoas envolvidas nos filmes exibidos em festivais com postagens nas redes sociais interfere no desempenho dos algoritmos e na programação por recomendação, como as existentes nos streamings.

Por que migrar, afinal? Para além da capacidade adaptativa que as circunstâncias exigem, vivemos em uma sociedade ocularcêntrica, na qual a imagem tem uma função epistêmica e simbólica (MACHADO PAIS, 2010), onde ser visto é uma questão de sobrevivência - ainda mais considerando que a cultura nacional convive com ataques sistemáticos, iniciados em 2013 (GUERRA, 2021) ${ }^{6}$, intensificado desde 2016, e culminando no atual governo com a desativação do Ministério da Cultura. Esse processo vem sendo marcado pelo desinvestimento em editais de cultura, de que é exemplo a suspensão das atividades da Cinemateca Brasileira, levando ao incêndio em um dos galpões que abrigava parte do acervo da instituição, em julho de $2021^{7}$. O desmonte da cultura do Brasil ganhou dimensão ainda maior principalmente pela paralisação da cena cultural por meio do desmantelamento da Lei Rouanet, da ineficiência da Secretaria Especial da Cultura, e da ausência de novos editais federais destinados ao setor de produção audiovisual, denunciada pela $O A B$ em maio de 2021. Esses fatores, como já mencionado, desvelam como a cultura e a comunicação são os alvos iniciais de controle por parte da agenda política neoliberal brasileira,

\footnotetext{
${ }^{6}$ GUERRA, Flávia. "Tragédia mais que anunciada da Cinemateca Brasileira”. Jornal Unesp, 6 ago. 2021. Disponível em: https://jornal.unesp.br/2021/08/06/a-tragedia-mais-que-anunciada-da-cinematecabrasileiral. Acesso em: 8 de novembro de 2021.

7 O incêndio na Cinemateca Brasileira foi discutido na Câmara do Deputados, em audiência pública transmitida pelo YouTube, em 17 de setembro de 2021. Cf. https://www.youtube.com/watch?v=c8gpmQt8EQE. Acesso em: 8 de novembro de 2021.
} 
marcadas pela extrema exploração econômica da máquina pública e pelo silenciamento de vozes contraditórias.

Os cotidianos do setor cultural e do cinema em particular são marcados por um processo contínuo de identificação das brechas oferecidas pelo sistema para expressar a resistência da produção cultural. Um cotidiano, nos termos de CERTEAU (1994), atualizado na convergência cultural em suas estratégias comunicativas já dominada pelas grandes corporações (JENKINS, 2008). O ciberespaço, caracterizado por várias ciberculturas, passa a ser disputado por novos agentes da produção cultural, como menciona NAYAR (2010). Entretanto, ALMEIDA (2020) considera algumas limitações para $\circ$ protagonismo cultural em ambiente virtualizado, devido às restrições das habilidades sociotécnicas requeridas dos consumidores. No cotidiano digital da pandemia, essa habilidade sociotécnica (BENAKOUCHE, 1999) passa a ser demandada também dos organizadores de festivais de cinema, que agora devem entender de lives, streaming, plataformas, entre outros quesitos tecnológicos. $\mathrm{O}$ artigo aqui proposto, desta forma, apresenta dados parciais do cenário atual de festivais de cinema organizados por brasileiros, a partir de pesquisa exploratória sobre o efeito econômico gerado no setor pelo fechamento das salas de exibição, considerando os seguintes aspectos no processo de virtualização ou adesão ao sistema online: 1) adaptação para a realização do festival no formato online; 2) modos de participação do público; 3) desafios relacionados à migração para o formato online e ações bem-sucedidas no contexto digital - o que funcionou em termos de tecnologia, comunicação com o público e proteção dos direitos autorais das obras.

\section{METODOLOGIA}

Inicialmente, formulou-se um questionário online, testado com uma amostra reduzida de dois participantes do meio cultural e, na sequência, adaptado para aplicação em larga escala. Essa primeira etapa ocorreu em meados de agosto de 2020. Validado o questionário piloto, com perguntas abertas e fechadas, foi gerado o questionário em Google Forms $^{8}$ para distribuição online, a ser respondido de forma voluntária por produtores de festivais de cinema. O período aceito para respostas foi durante todo 0 mês de setembro de 2020. O formulário foi distribuído por e-mail e divulgados nas redes e em grupos sociais da área de audiovisual e cinema desde o início de setembro de 2020. Consideramos um alcance de notificação de recebimento do formulário de 50

\footnotetext{
${ }^{8}$ O questionário gerado em Google Forms é uma ferramenta oferecida para quem possui conta do gmail, permite gerar perguntas de múltiplas escolhas, perguntas abertas com respostas curtas, e perguntas abertas com respostas longas, muito utilizado em pesquisa quantitativa, por gerar gráficos e outras análises via tabela do excell associado ao questionário. (Andres et. al. 2020)
} 
entidades organizadoras de festival, seja pela confirmação do recebimento do e-mail, seja por interação com o conteúdo nas redes sociais, de um universo geral de 350 festivais no Brasil. Entretanto, deste universo foram considerados os festivais que estavam em sua quarta edição em diante, para permitir a percepção do processo de adaptação para o ambiente virtual. A partir desse critério foram considerados válidos 31 dos 50 respondentes, sendo que um deles respondeu o formulário referente à organização de três festivais sob seu comando, totalizando 33 respostas. Os dados e as análises do Mapa de Mostras e Festivais (ANCINE, 2020) e do Guia de Festivais Kinoforum 2019 (CORREA, 2020) foram considerados como dados complementares da pesquisa.

Como parte do método, cabe-nos descrever brevemente, ainda, o contexto em que se configura o setor de festivais a partir da Economia do Audiovisual e Economia Criativa no que concerne aos novos cenários socioeconômicos. Os festivais de cinema do Brasil têm suas origens no início dos anos 1950 e vivem um contexto de maior expansão a partir dos anos 1990, especialmente com a criação do Festival Internacional de Curtas-metragens de São Paulo e da Mostra Curta Cinema (RJ), além de festivais específicos como o Anima Mundi (animação) e o É tudo Verdade (documentários) (MAGER, 2021). A nossa análise parte de informações contemporâneas compiladas no Diagnóstico Setorial 2007/Indicadores 2006, analisadas por Mattos e Leal (2009), nas quais importa compreender a geração de emprego e renda no setor de eventos audiovisuais, relevantes para a análise abordada neste artigo:

Os dados revelados na área de geração de emprego e movimentação financeira são outra fonte reveladora da potencialidade dos eventos audiovisuais. Foram movimentados 60 milhões de reais em 2006, gerando um nível médio de postos de trabalho de 45,31 empregos por festival e 6 mil contratações. No campo econômico, foi possível perceber também que os orçamentos efetivos dos festivais estão, em sua larga maioria, limitados ao teto de 300 mil reais (MATTOS; LEAL, 2009).

O conceito de Economia Criativa é entendido como bens e produtos gerados por uma indústria "das ideias" e, no segmento audiovisual, contempla os produtos tangíveis, serviços intelectuais com conteúdo criativo e de valor econômico, capazes de estimular a geração de empregos e renda, com base em saberes artísticos, técnicos e culturais (UNCTAD, 2019). De acordo com o Mapeamento da Indústria Criativa (2019), a análise do crescimento do campo de produção de criatividade é feita sob duas 
perspectivas: áreas de atuação dos profissionais criativos, e valor de produção gerado pelos estabelecimentos criativos, tendo como base dados oficiais do Ministério do Trabalho. As profissões são apresentadas em treze segmentos criativos: Arquitetura, Artes Cênicas, Audiovisual, Biotecnologia, Design, Editorial, Expressões Culturais, Moda, Música, Patrimônio e Artes, Pesquisa e Desenvolvimento, Publicidade e Marketing, e TIC.

Nesse sentido, os festivais de cinema situam-se no campo de produção de criatividade que expressa valor na interação com as áreas de exibição, distribuição de filmes de formatos heterogêneos, além de rodadas de negócios para novas produções. São caracterizados pela diversidade de temas, perfis, conceitos e objetivos inerentes a cada evento (MATTOS, 2013). Para além da promoção de filmes e artistas, homenagens e curadorias temáticas, os festivais configuram potenciais espaços para engajamento midiático, além do destaque de patrocinadores e apoiadores. Essa dinâmica e a possibilidade de programação especial confere aos festivais características específicas no mercado de exibição, como a democratização de acesso, a possibilidade de formação por meio de debates, oficinas e palestras com as realizadoras(es) dos filmes, e o ineditismo de algumas obras e divulgação de acervo audiovisual.

Muitas vezes, as mostras e festivais são a primeira porta de entrada de uma obra audiovisual, além de serem os principais canais de difusão de obras de novos realizadores, de curtas-metragens e de produções nacionais e estrangeiras não exibidas em circuito comercial. Além disso, o estímulo à exibição cinematográfica e a possibilidade de levar o cinema e a produção audiovisual até o público nas cidades mais distantes dos grandes centros são também objetivos de realizadores de mostras e festivais (Mapa de Mostras e Festivais, ANCINE, 2020).

No Brasil, em 2019, mais de 350 festivais de cinema atraíam em média 2,5 milhões de espectadores por ano, mais que o dobro de 2006, quando foram registrados 132 festivais, segundo dados do Guia de Festivais Kinoforum 2019 (CORREA, 2020). Até março de 2020, por ocorrer de modo presencial, esse aumento movimentava a economia e o turismo. O cenário mudou drasticamente quando diversos eventos foram subitamente cancelados em decorrência da pandemia de Covid-19. O estado mais impactado foi São Paulo, onde ocorriam mais de 50\% dos festivais (CORREA, 2020). Com isso, importa identificar e compreender as alternativas para a realização das mostras e festivais, e compreender quais as principais dificuldades e expectativas para 
o setor no cenário digital, a partir da observação dos dados gerados pelo questionário aplicado aos 33 eventos participantes dessa pesquisa. Os dados de identificação dos informantes foram mantidos em sigilo atendendo a procedimentos ético na pesquisa qualitativa, compreendendo que a exposição dos nomes pessoais ou dos festivais poderia acarretar algum tipo de prejuízo, visto que estão em um campo de disputa por legitimação.

As categorias definidas para a análise das repostas do formulário procuraram atender a três grupos de interesse dessa pesquisa: 1) adaptações para a realização do festival no formato online - conjunto de procedimentos e táticas empregadas na reconfiguração das relações sociais inerentes ao evento e à experimentação de técnicas para se recriar experiências de exibição dos filmes; 2) modos de participação do público no formato online - refere-se a uma nova compreensão da estética da recepção no ambiente da cibercultura, e a noção de interatividade e engajamento; 3) desafios e ações bem-sucedidas no formato online.

A opção por apresentar os resultados em conjunto com as discussões nos permite correlacionar os dados com o referencial teórico mais prontamente, organizando a lógica de raciocínio para as considerações finais.

\section{RESULTADOS E DISCUSSÃO}

\section{1) Adaptação para a realização do festival no formato online}

A realização dos festivais no formato online trouxe à tona alternativas e também problematizações sobre o alcance dos eventos para além das exibições dos filmes. Uma das problematizações foi a relação da realização dos festivais com o turismo nas cidades onde eles ocorrem, movimentando a cadeia de restaurantes e hotéis, esmaecida com a migração para o virtual. Outra área afetada foi a de rodada de negócios para parcerias em coprodução, que normalmente ocorriam em pitchings ${ }^{9}$ presenciais, e em alguns casos migraram igualmente para o online. Um ponto que emergiu de forma positiva foi o acesso facilitado permitido pelo sistema online às curadorias especiais temáticas ou por gênero cinematográfico, que fizeram frente ao consumo desenfreado de conteúdos ofertados pelas plataformas convencionais de streaming. Diante desse quadro ainda novo para ser avaliado, o setor encontrou, nesse período, algumas estratégias em comum de "invenção" do cotidiano (CERTEAU, 1994), principalmente em relação à reapropriação das ferramentas disponíveis no mercado digital para a criação de uma outra experiência de consumo de produtos audiovisuais "descentralizada" dos grandes

${ }^{9}$ Pitching: Uma breve forma de apresentação de projetos utilizado no meio cinematográfico com o objetivo de conseguir investimento e/ou apoio cultural para o projeto de filme ou série (BALAKHONSKAYA et. al., 2021). 
mercados exibidores. A operação para adaptar um evento presencial em formato online abarca um conjunto de procedimentos e táticas empregadas para dois fins principais: a reconfiguração das relações sociais inerentes ao evento e a experimentação de técnicas para se recriar experiências objetivas, como a perfeita exibição dos filmes, e subjetivas, baseadas nos valores e sentimentos do público. As respostas à pesquisa apontam a predominância de algumas dessas articulações, assim classificadas: a) adaptação das experiências; b) readequação da linguagem para o digital; e c) mudanças no modelo de produção (gestão e trabalho em equipe). Foram identificadas as seguintes ações (Tabela 1):

Tabela 1 - Adaptação ao sistema online de exibição

\begin{tabular}{|c|c|c|}
\hline $\begin{array}{l}\text { (a) Adaptação das } \\
\text { experiências }\end{array}$ & $\begin{array}{l}\text { (b) Readequação da } \\
\text { linguagem para o digital }\end{array}$ & $\begin{array}{l}\text { (c) Mudanças no modelo } \\
\text { de produção (gestão e } \\
\text { trabalho em equipe) }\end{array}$ \\
\hline $\begin{array}{l}\text { Festival } 100 \% \text { digital e } \\
\text { autorização de todas as } \\
\text { produções para permitir a } \\
\text { exibição online, o que não é } \\
\text { praxe no audiovisual, pois a } \\
\text { maioria dos festivais exige que } \\
\text { as produções sejam originais } \\
\text { e/ou não tenham sido } \\
\text { veiculadas em nenhuma } \\
\text { plataforma online. }\end{array}$ & $\begin{array}{l}\text { Contratação de plataforma para } \\
\text { se exibir as obras e as } \\
\text { atividades propostas. }\end{array}$ & Reuniões online. \\
\hline $\begin{array}{l}\text { Adaptação para a forma virtual } \\
\text { de projetar videodança em } \\
\text { forma online e não presencial } \\
\text { com oficinas e mesas } \\
\text { temáticas. }\end{array}$ & $\begin{array}{l}\text { Construção de site próprio para } \\
\text { o Festival. }\end{array}$ & $\begin{array}{l}\text { Monitoramento das } \\
\text { exibições e análise do } \\
\text { público presente nas redes } \\
\text { sociais. }\end{array}$ \\
\hline $\begin{array}{l}\text { Mudanças no formato de } \\
\text { exibição, realização de oficina } \\
\text { online, show e festa online. }\end{array}$ & $\begin{array}{l}\text { Criação de um modelo "híbrido" } \\
\text { em que a abertura e o } \\
\text { encerramento serão no modelo } \\
\text { cine drive-in, enquanto as } \\
\text { mostras e oficinas serão todas } \\
\text { online, em plataforma própria (o } \\
\text { que fomentou uma inovação na } \\
\text { área de audiovisual dentro da } \\
\text { instituição). }\end{array}$ & $\begin{array}{l}\text { Mudança da abertura de } \\
\text { inscrições de nível estadual } \\
\text { para nacional. }\end{array}$ \\
\hline $\begin{array}{l}\text { Adiamento da e criação de } \\
\text { braço online de curadoria }\end{array}$ & $\begin{array}{l}\text { Maior demanda de uso das } \\
\text { redes sociais para engajamento } \\
\text { do público, mudança da }\end{array}$ & $\begin{array}{l}\text { Criação de grupos de } \\
\text { trabalho no Whatsapp. }\end{array}$ \\
\hline
\end{tabular}




\begin{tabular}{|c|c|c|}
\hline $\begin{array}{l}\text { expandida, com sessões de } 2 \\
\text { curtas por semana + debate. }\end{array}$ & $\begin{array}{l}\text { quantidade de atividades, como } \\
\text { oficinas, palestras e filmes. }\end{array}$ & \\
\hline $\begin{array}{l}\text { Diminuição do tempo de } \\
\text { duração do festival e } \\
\text { realização de todas as } \\
\text { atividades online, com foco em } \\
\text { convidar mais pessoas de todo } \\
\text { o Brasil e promover uma maior } \\
\text { diversidade regional. }\end{array}$ & $\begin{array}{l}\text { Uso extensivo de redes sociais } \\
\text { para comunicação da equipe, } \\
\text { divulgação e engajamento. }\end{array}$ & $\begin{array}{l}\text { Desenvolvimento de } \\
\text { plataforma de streaming } \\
\text { para exibição dos filmes. }\end{array}$ \\
\hline $\begin{array}{l}\text { Filmes disponíveis por } 24 \mathrm{~h} \mathrm{e} \\
\text { debate com as realizadoras, }\end{array}$ & $\begin{array}{l}\text { Readequação de toda a } \\
\text { estratégia de divulgação. }\end{array}$ & $\begin{array}{l}\text { Investimento estratégico em } \\
\text { marketing digital. }\end{array}$ \\
\hline $\begin{array}{l}\text { O evento em vez de local, } \\
\text { passou a ser nacional. A } \\
\text { negociação de direitos de } \\
\text { exibição foi mais detalhada, } \\
\text { com exigência de geobloqueio. }\end{array}$ & & $\begin{array}{l}\text { Distribuição de funções } \\
\text { restrita às ferramentas } \\
\text { online: redes sociais, } \\
\text { assessoria de imprensa, site } \\
\text { e arte. }\end{array}$ \\
\hline
\end{tabular}

Das 33 respostas válidas ao questionário, 22 indicaram mudanças efetivas na adaptação da experiência para o formato online, considerando principalmente as estratégias de comunicação e transição do cinema presencial para plataformas de streaming. Vale destacar que o meio predominante para a exibição de filmes, oficinas, debates e shows foi o YouTube (12), seguido de Facebook e Instagram pelos canais e perfis oficiais dos Festivais e Mostras (3), do Vimeo (3) e de plataformas próprias (1), além de canais próprios para exibição (10) e duas plataformas nacionais de serviços de streaming: Looke (1) e VideoCamp (1). Os dados revelam a heterogeneidade na escolha de canais para exibição, jogando luz às questões orçamentárias de adequação do perfil do evento aos serviços que melhor dialoguem com o público, mantendo algumas características centrais das mostras e dos festivais. As principais atitudes em relação à estratégia de comunicação dos festivais nas redes sociais em um contexto em que se observou a grande oferta de filmes e conteúdos gratuitos, foram: intensificar a presença digital por meio da produção de conteúdos, e a movimentação contínua nas redes, especialmente Facebook e Instagram. Para 22 respondentes foi preciso desenvolver planejamentos estratégicos com foco prioritário na divulgação de conteúdo online para gerar novas conexões para a comunicação em rede com o apoio de multiplicadores nas diversas esferas do setor produtivo da cadeia do audiovisual e também outros atores sociais. Destaca-se que muitos festivais optaram pela ressignificação da linguagem do evento para o ambiente virtual, mesclando conteúdos informativos e institucionais à própria dinâmica de entretenimento das redes, como o uso de memes, lives e humor, e também a uma melhor organização dos conteúdos nas redes sociais, o que não 
acontecia quando os eventos eram presenciais. A segmentação do público e o investimento pago para anúncios foram apontados como formas de fazer com que os conteúdos chegassem às pessoas certas e interessadas nas especificidades de cada mostra/festival.

\section{2) Modos de participação do público no formato online}

Dentre as muitas reflexões possíveis sobre a relação do público com as mostras e os festivais online, destacamos duas principais: a primeira se refere a uma nova compreensão da estética da recepção no ambiente da cibercultura, e a segunda parte das noções de interatividade (MANOVICH, 2011; DA SILVA et. al., 2020) e engajamento proposta pelos autores Jenkins e Ford (2014), em Cultura da Conexão. A recepção cinematográfica no ambiente virtual difere da experiência presencial do cinema, principalmente porque a lógica do "espectador-receptor" e o consumo de produção midiática operam por métricas de mercado diferentes, ainda que exista o esforço para "transpor" a experiência presencial para o ambiente online. Alguns recursos facilitadores permitem uma emulação do presencial, como a presença do apresentador antes das sessões online ou o bate-papo com diretores antes da exibição dos filmes. Entretanto, a própria experiência de cinema é modificada pelo poder dado à audiência de acelerar as falas, pular a parte institucional ou os créditos, tornando radical a noção do consumo de imagens na era hiperconectada. Deste modo, o espectador é entendido como uma variável interveniente, pois agora pode personalizar o que deseja assistir - afetando o que foi idealizado pela curadoria. A experiência fica mais próxima do modelo de streaming, no qual as plataformas funcionam por programação algorítmica dos gostos e preferências. Desse modo, ocorre a desconstrução da noção de sequenciamento de filmes existente em muitos festivais, principalmente os que aceitam curtas-metragens.

O outro ponto refere-se à participação e ao engajamento nas atividades culturais coletivas, que configuram o campo de construção de sentido a partir de interesses em comum. $\mathrm{O}$ engajamento configura, na experiência dos festivais online, a relevância do indivíduo no processo de constituição de sentidos deste ou outro evento audiovisual. Esse valor simbólico manifesta-se por meio das escolhas do que assistir, de quais mensagens incorporar e como isso se constitui a partir das construções culturais, temáticas, políticas e identitárias do espectador. A participação, portanto, não é somente assistir ao filme, mas comentar sobre os filmes nas redes sociais, escolher receber avisos no e-mail, compartilhar as preferências nas diversas plataformas e participar ativamente da promoção do festival ou mostra, a partir desse viés de criação e inteligência coletiva. 


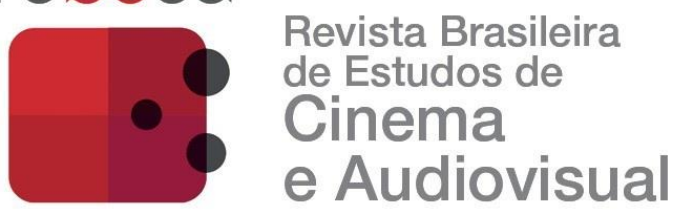

Essa foi uma das questões que trouxemos para averiguar quais os impactos da mudança dos eventos para o formato online considerando o engajamento e a interação com o público. Participar dos festivais online não foi somente uma experiência nova, mas um ato de inclusão digital para uma parte do público, e de inclusão cultural para outra parte, que antes não tinha acesso devido à distância geográfica e condições financeiras. Considerando as respostas que apontam transformações nessa dinâmica, organizamos a Tabela 2, na qual o aumento do engajamento está relacionado ao compartilhamento ou aos comentários em postagens sobre os festivais, por pessoas não diretamente ligadas ao evento (a); quais as especificidades das ações adaptadas para o virtual (b); pelos comentários nos chats durante as lives ou exibições virtuais dos eventos (c), também por pessoas não diretamente ligadas ao evento; e o modo como foram realizadas as votações em filmes nos festivais no ambiente online (d):

Tabela 2 - Modos de participação do público

\begin{tabular}{|c|c|c|c|}
\hline $\begin{array}{l}\text { (a) Aumento de } \\
\text { engajamento } \\
\text { graças ao } \\
\text { envolvimento do } \\
\text { público }\end{array}$ & $\begin{array}{l}\text { (b) Atividades } \\
\text { e ações } \\
\text { adaptadas para } \\
\text { o virtual }\end{array}$ & $\begin{array}{l}\text { (c) Presença do público } \\
\text { por meio de interações: } \\
\text { chats e comentários }\end{array}$ & (d) Voto popular \\
\hline $\begin{array}{l}\text { Alcance em mais de } \\
50 \text { países. }\end{array}$ & $\begin{array}{l}\text { Projeções online } \\
\text { e público online. }\end{array}$ & $\begin{array}{l}\text { A participação do público } \\
\text { será online através da } \\
\text { plataforma de streaming. Os } \\
\text { cineastas vão ter acesso } \\
\text { também a todos os } \\
\text { comentários deixados pelos } \\
\text { usuários. }\end{array}$ & $\begin{array}{l}\text { Os votos do júri } \\
\text { popular foram } \\
\text { computados online } \\
\text { através de cadastro } \\
\text { em plataforma de } \\
\text { streaming. }\end{array}$ \\
\hline $\begin{array}{l}\text { Aumento depois que } \\
\text { o evento se tornou } \\
100 \% \text { online. }\end{array}$ & $\begin{array}{l}\text { Filmes online, } \\
\text { sem público } \\
\text { presente. }\end{array}$ & $\begin{array}{l}\text { Bate-papos entre } \\
\text { profissionais de audiovisual } \\
\text { do mercado e da academia } \\
\text { e também uma Mostra de } \\
\text { Curtas, mantendo o } \\
\text { reconhecimento e promoção } \\
\text { de produções universitárias, } \\
\text { porém sem o caráter } \\
\text { competitivo. }\end{array}$ & $\begin{array}{l}\text { Ao término de cada } \\
\text { sessão será } \\
\text { disponibilizado o } \\
\text { acesso para votação } \\
\text { do público. }\end{array}$ \\
\hline $\begin{array}{l}\text { O público ajudou a } \\
\text { divulgar mais do que }\end{array}$ & $\begin{array}{l}\text { Incentivos à } \\
\text { participação }\end{array}$ & $\begin{array}{l}\text { Realização de lives } \\
\text { aproximando o debate e }\end{array}$ & $\begin{array}{l}\text { Antes nas sessões } \\
\text { presenciais os }\end{array}$ \\
\hline
\end{tabular}




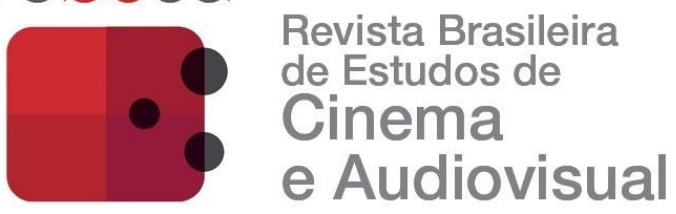

\begin{tabular}{|c|c|c|c|}
\hline na versão presencial. & online. & $\begin{array}{l}\text { exibição dos filmes junto ao } \\
\text { público. }\end{array}$ & $\begin{array}{l}\text { espectadores } \\
\text { votavam em células } \\
\text { físicas e agora } \\
\text { seguirão votando, } \\
\text { porém de modo } \\
\text { virtual. }\end{array}$ \\
\hline $\begin{array}{l}\text { Além da ampliação } \\
\text { da divulgação } \\
\text { daqueles que } \\
\text { inscreveram as } \\
\text { obras, houve maior } \\
\text { engajamento e } \\
\text { difusão das redes } \\
\text { sociais da entidade } \\
\text { organizadora. }\end{array}$ & $\begin{array}{l}\text { Diminuição de } \\
\text { custos de } \\
\text { produção de } \\
\text { materiais como: } \\
\text { cartazes, } \\
\text { banner, } \\
\text { camisetas e } \\
\text { demais itens } \\
\text { promocionais. }\end{array}$ & $\begin{array}{l}\text { Este ano o festival foi } \\
\text { realizado totalmente de } \\
\text { forma digital, com exibições } \\
\text { no YouTube e com chat } \\
\text { aberto para interação e } \\
\text { perguntas. }\end{array}$ & $\begin{array}{l}\text { As mostras } \\
\text { competitivas serão } \\
100 \% \text { online, com } \\
\text { votação do público } \\
\text { por meio de } \\
\text { aplicativo } \\
\text { desenvolvido pela } \\
\text { entidade } \\
\text { organizadora. }\end{array}$ \\
\hline $\begin{array}{l}\text { Aumento do público } \\
\text { alcançado e } \\
\text { manutenção do } \\
\text { público local e } \\
\text { regional que } \\
\text { costumava } \\
\text { acompanhar o } \\
\text { festival. }\end{array}$ & $\begin{array}{l}\text { Adequação para } \\
\text { mostra online. } \\
\text { Novas parcerias } \\
\text { por conta da } \\
\text { pandemia. }\end{array}$ & $\begin{array}{l}\text { Esse ano não terá voto } \\
\text { popular, mas terá oficinas de } \\
\text { vídeodança abertas para } \\
\text { interessados nacionais e } \\
\text { internacionais e por ser em } \\
\text { uma plataforma online, } \\
\text { possibilidade de abranger } \\
\text { novos públicos. }\end{array}$ & $\begin{array}{l}\text { O voto popular se } \\
\text { deu por meio de } \\
\text { aplicativo anexado à } \\
\text { página do festival no } \\
\text { Facebook. }\end{array}$ \\
\hline $\begin{array}{l}\text { Aumento do público } \\
\text { além da plateia } \\
\text { regional. }\end{array}$ & $\begin{array}{l}\text { Desenvolviment } \\
\text { o de habilidades } \\
\text { para melhor lidar } \\
\text { com a } \\
\text { comunicação } \\
\text { digital. }\end{array}$ & $\begin{array}{l}\text { A participação se voltou } \\
\text { principalmente às redes } \\
\text { sociais, com comentários e } \\
\text { perguntas em lives das } \\
\text { sessões. }\end{array}$ & $\begin{array}{l}\text { Decidimos pela } \\
\text { votação interna, } \\
\text { disponível apenas } \\
\text { para participantes } \\
\text { cadastrados. }\end{array}$ \\
\hline $\begin{array}{l}\text { Maior engajamento } \\
\text { de realizadores para } \\
\text { divulgação do } \\
\text { festival. }\end{array}$ & $\begin{array}{l}\text { Direcionamento } \\
\text { de conteúdos } \\
\text { para público } \\
\text { segmentado. }\end{array}$ & $\begin{array}{l}\text { O público assistiu os filmes, } \\
\text { que ficaram disponíveis por } \\
24 \mathrm{~h} \text {, e puderam acompanhar } \\
\text { a live de debate sobre os } \\
\text { filmes ao vivo, participando } \\
\text { através de chat. }\end{array}$ & $\begin{array}{l}\text { Sistematizar o voto } \\
\text { válido somente entre } \\
\text { os cadastrados que } \\
\text { assistirem a todos } \\
\text { os filmes, pois é } \\
\text { assim durante o } \\
\text { festival quando é } \\
\text { presencial. }\end{array}$ \\
\hline Ampliação dos & Adaptação de & O público participará apenas & Necessidade de \\
\hline
\end{tabular}




\begin{tabular}{|l|l|l|l|}
\hline $\begin{array}{l}\text { espectadores para } \\
\text { além do público }\end{array}$ & $\begin{array}{l}\text { cursos, oficinas } \\
\text { e debates para o } \\
\text { contumaz de } \\
\text { fostivais. }\end{array}$ & $\begin{array}{l}\text { nos painéis temáticos - não } \\
\text { haverá escolha do público } \\
\text { para filmes. }\end{array}$ & $\begin{array}{l}\text { fomentar o } \\
\text { comprometimento } \\
\text { do júri no ambiente } \\
\text { digital. }\end{array}$ \\
\hline
\end{tabular}

Nesse processo de participação, podemos verificar que, quando viabilizada, houve maior preocupação com a qualidade e a seriedade dos organizadores dos festivais, para validar o processo mediado por uso de tecnologia remota. Nesse sentido, dialoga-se com PROULX (2010): ainda que os usos das tecnologias se deem em contextos heterogêneos e plurais, será por meio das regras e procedimentos inerentes aos festivais e mostras que esses usos vão se consolidar. A questão central parece ser o controle da mobilização digital passível de ser promovida pelos diretores participantes das mostras competitivas, o que falsearia o resultado das votações. Nesse aspecto, é sugestivo o controle das estratégias da participação de público. Ressaltamos, como indicado no início do artigo, a necessidade de engajamento com os cineclubes, como demonstrado na resposta "maior engajamento e difusão das redes sociais do Coletivo Audiovisual Negro Quariterê", pois auxiliam na construção da criticidade da linguagem audiovisual por parte dos participantes. Dessa forma, pelas experiências mesmo no campo presencial constatada por uma das autoras - que é também diretora de festival e por questões éticas se absteve de responder o questionário -, já havia a indicação de necessidade de controle na votação, ou seja, não vemos emergir novos códigos gerando novas condutas, mas sim velhos hábitos em nova roupagem. A tecnologia social tem suas limitações tanto na direção de quem produz quanto na de quem utiliza.

\section{3) Desafios e ações bem-sucedidas no contexto digital de cinema online}

O principal objetivo de toda mostra ou todo festival audiovisual é fazer com o que público participe de modo interativo das atividades propostas e para validar a programação selecionada para o evento. Nesse sentido, Manovich (2011) projeta que o cenário típico do cinema no século XXI permitirá que o usuário possa ser representado como um avatar e experencie os filmes de dentro, interagindo com personagens ou afetando o curso dos eventos narrativos - o que já é uma realidade com os filmes $360^{\circ}$ e com os de Realidade Ampliada. O quanto essas possiblidades aumentam com a migração dos festivais para o online? Qual a tendência dos filmes experimentais a esse respeito? O público, junto a outros agentes do setor, garante a continuidade e a relevância dos festivais, dando visibilidade para o cinema independente, para 0 audiovisual brasileiro e abrindo possibilidades na indústria criativa para cineastas 
iniciantes e diversos profissionais do segmento. Nesse sentido, um dos grandes desafios é o de atrair o público e ampliar o alcance dos eventos. Categorizamos as respostas desse tópico em três tipos:

a) Interação e engajamento com o público

A dificuldade de interação e engajamento com o público foi apontada como uma das principais barreiras à efetiva experiência de participação nos festivais e mostras realizadas online, destacando principalmente o obstáculo de chegar até o público e/ou diversificá-lo. Dentre os pontos levantados, pontuamos a dificuldade colocada de se mapear e conhecer a "jornada de compra", por assim dizer, do indivíduo consumidor de conteúdos audiovisuais e contumaz frequentador de eventos de cinema, agora no ambiente online. Para organizadoras(xs) dos festivais, esse é um aspecto que precisa ser estudado, porque se notou um verdadeiro abismo entre a oferta do conteúdo e a decisão de compra/escolha. Aponta-se que a própria dinâmica da produção de comunicação dentro do mercado digital implica o conhecimento de algumas habilidades que escapam à formação de quem não é da área de marketing, por exemplo.

O caráter efêmero dos conteúdos postados nas redes sociais também apareceu como um ponto a ser observado no planejamento de comunicação dos festivais, uma vez que muito conteúdo acabou tendo baixo engajamento pelo excesso de informação inerente ao ambiente virtual.

A dificuldade de troca com o público ficou latente para 5 dos 31 respondentes ao questionário, que mencionaram as características das plataformas como empecilhos à fala ou troca de impressões sobre os filmes e debates. Isso traz à tona uma lacuna que pode ser até uma potencial área de atuação no audiovisual, qual seja, a necessidade de mapear profissionais da tecnologia que tenham visão específica para festivais, reclamação comum tanto do público - aqui representado pela outra autora do artigo -, quanto de quem estava envolvido na produção dos eventos.

\section{b) Qualidade das exibições e dificuldade de acesso à internet}

Para aquelas(es) que mencionaram o desejo de dar continuidade a uma ou mais atividades ofertadas pelos eventos na modalidade online, duas questões urgentes surgiram: a qualidade das transmissões e o acesso à internet. Sete respondentes consideram que esses são os maiores obstáculos para a realização dos eventos, visto que a qualidade da oferta de serviços de internet varia muito no Brasil, o que afeta ambos os aspectos. Parte do público que não tem acesso regular à internet fica impossibilitado de conhecer e participar de festivais online, o que descaracteriza a própria essência dos eventos, que é a de promover o cinema para diferentes públicos. Soma-se a isso que as interrupções e quebras no processo de comunicação tendem a afastar o espectador e 
prejudicar a própria exibição de um filme, limitando a experiência, visto que uma transmissão de conteúdo depende da velocidade e qualidade da internet de quem emite a informação, mas também da velocidade e qualidade de quem recebe os conteúdos, principalmente em se tratando de audiovisual e cinema, e mais ainda se for no sistema "live/ao vivo" ou "streaming".

\section{c) Proteção aos Direitos autorais}

Dentre as preocupações com os direitos autorais, quatro respondentes indicaram a necessidade de se ampliar o cuidado para proteger as obras de downloads e distribuição "ilegais", por um lado, e de estudar as exceções relacionadas à exibição de algumas obras no formato online, considerando o futuro desses filmes no mercado audiovisual - com base na cultura de gratuidade e compartilhamento que se choca com a própria dinâmica de produção dos conteúdos audiovisuais à luz da indústria criativa. Um outro impasse, mencionado por outros quatro dos pesquisados, foi justamente decidir se os conteúdos das oficinas e webinários deveriam ser gratuitos, devido a prática habitual de youtubers em ofertar diversos materiais e aulas gratuitamente, em um primeiro momento, para depois oferecer conteúdo pago.

Algumas ações foram consideradas bem-sucedidas pelas organizadoras(es)(xs) das mostras e festivais no formato online. $\mathrm{Na}$ Tabela 3 , apresentamos as práticas e os respectivos resultados, das estratégias mencionadas para a exibição na pós-pandemia, subdivididas em três tipos: a) ações para maior alcance do Festival/Mostra; b) intensificação da produção de conteúdo para maior presença digital; c) criação de um modelo híbrido do evento.

Tabela 3 - Estratégias híbridas para exibição Pós-Pandemia

\begin{tabular}{|l|l|l|}
\hline $\begin{array}{l}\text { (a) Maior alcance do } \\
\text { Festival/Mostra }\end{array}$ & $\begin{array}{l}\text { (b) Produção de conteúdo/ } \\
\text { presença digital }\end{array}$ & (c) Modelo híbrido do evento \\
\hline $\begin{array}{l}\text { Compartilhamento e maior } \\
\text { redes sociais, principalmente } \\
\text { o Instagram. }\end{array}$ & $\begin{array}{l}\text { Alimentação constante das } \\
\text { redes sociais antes, durante a realização do } \\
\text { festival. }\end{array}$ & $\begin{array}{l}\text { Criação de um evento híbrido de } \\
\text { Difundional. essa nova forma híbrida } \\
\text { de arte para um novo público } \\
\text { online e despertar o interesse de } \\
\text { todos. }\end{array}$ \\
\hline $\begin{array}{l}\text { Facilidade tecnológica para o nas } \\
\text { júri oficial trabalhar nas } \\
\text { avaliações. }\end{array}$ & $\begin{array}{l}\text { Criação da plataforma de } \\
\text { streaming. }\end{array}$ & $\begin{array}{l}\text { Criação de Oficina Virtual para } \\
\text { alcançar pessoas de outros } \\
\text { estados, além de São Paulo. }\end{array}$ \\
\hline
\end{tabular}




\begin{tabular}{|c|c|c|}
\hline $\begin{array}{l}\text { Tivemos } 373 \text { filmes inscritos, } \\
\text { um aumento de } 83 \% \text { em } \\
\text { relação ao ano passado, foi } \\
\text { o maior número desde a } \\
\text { primeira edição em } 2016 \text {. }\end{array}$ & $\begin{array}{l}\text { Manutenção do site. } \\
\text { Mostras não competitivas } \\
\text { menores. }\end{array}$ & $\begin{array}{l}\text { Lives com diretores, o que ajuda } \\
\text { a ter perto pessoas de outros } \\
\text { estados que não poderiam estar } \\
\text { presentes fisicamente. }\end{array}$ \\
\hline $\begin{array}{l}\text { Maior alcance do audiovisual } \\
\text { de maneira geral. Em } \\
\text { espaços fechados, de } \\
\text { maneira presencial, } \\
\text { atingimos número limitado de } \\
\text { plateia. }\end{array}$ & $\begin{array}{l}\text { Realização de lives com } \\
\text { convidados negros/negras } \\
\text { profissionalmente } \\
\text { consolidados. }\end{array}$ & $\begin{array}{l}\text { Realização de oficinas em } \\
\text { ambiente digital. }\end{array}$ \\
\hline $\begin{array}{l}\text { Estávamos buscando e } \\
\text { precisando de mudanças. A } \\
\text { pandemia nos obrigou a sair } \\
\text { e desapegar de formatos } \\
\text { usuais. }\end{array}$ & $\begin{array}{l}\text { Inscrição por plataforma de } \\
\text { festivais, curadoria online. }\end{array}$ & $\begin{array}{l}\text { As exibições atingiram maior } \\
\text { quantidade de público. Mesmo } \\
\text { que o festival tenha momentos } \\
\text { presenciais novamente, o intuito } \\
\text { é manter exibições também em } \\
\text { paralelo de maneira online, e } \\
\text { realizar digitalmente também a } \\
\text { premiação. }\end{array}$ \\
\hline $\begin{array}{l}\text { Ampliamos o alcance dele a } \\
\text { um nível nacional e não } \\
\text { apenas local ou de } \\
\text { proximidades. }\end{array}$ & $\begin{array}{l}\text { Workshops, oficinas e } \\
\text { mesas temáticas com a } \\
\text { participação de pessoas do } \\
\text { Brasil e exterior. }\end{array}$ & $\begin{array}{l}\text { Seguir com oficina virtual } \\
\text { destinada ao público fora das } \\
\text { duas cidades atendidas } \\
\text { fisicamente pelo festival (SP- } \\
\text { RJ). }\end{array}$ \\
\hline $\begin{array}{l}\text { O festival pode e deve ter } \\
\text { alcance nacional - no que } \\
\text { concerne à exibição de } \\
\text { filmes - e mundial, no que } \\
\text { concerne aos painéis } \\
\text { temáticos. }\end{array}$ & $\begin{array}{l}\text { Transmissão ao vivo de } \\
\text { debates e workshops pelo } \\
\text { canal no YouTube. }\end{array}$ & $\begin{array}{l}\text { Abrir convocatória para novos } \\
\text { curadores de todo o Brasil, e } \\
\text { com isso pretendemos furar a } \\
\text { bolha de programação do } \\
\text { Sudoeste. }\end{array}$ \\
\hline
\end{tabular}

A ampliação do escopo de participação de diretores de filmes e da audiência sofreu alguma dificuldade em função do excesso de oferta e da falta de mecanismos mais adequados em termos algorítmicos para atingir de modo mais efetivo o público que gosta de novidades no cinema, seja em linguagem ou temática. Entretanto, observouse que ainda assim a maioria refere aumento e ampliação das atividades se comparadas as edições anteriores, o que indica a possibilidade de permanência de algumas ações 
no período pós-pandemia, com a oferta de conteúdo ao longo do ano e atividades presenciais mais pontuais, favorecendo um engajamento de público mais perene.

Os feedbacks em termos de comentários, curtidas e compartilhamentos passaram a compor os indicadores de participação do público, sendo utilizados como dados estatísticos para justificar patrocínios e apoio cultural. Com o aumento da visibilidade cresce também a preocupação com a qualidade dos eventos, estimulando a abertura de chamada para novas curadorias e ofertas de oficinas e masterclass. É possível analisar essa relação mediada a partir das proposições de PRIMO (2013) e considerar que as customizações das interfaces de sites e plataformas que exibem festivais online são definidas para ampliar a participação do público, ou seja, a interatividade. Esse fator justifica que a maioria dos respondentes tenha optado pela plataforma do YouTube, em resposta ao Tópico 1 dos resultados, ainda que nenhuma plataforma esteja a salvo de downloads indevidos, o YouTube é a plataforma que convive com o maior número de mecanismos de download irregular, até por ser a mais acessada, por isso investe constantemente na área de segurança. A isso se soma a preocupação com os direitos autorais e de imagem de tudo que circula a partir dos festivais na internet. Nesse campo de disputas e de estabelecimento de uma presença cultural digital, como abordado por NAYAR (2010), percebemos que as estratégias adotadas procuraram criar experiências singulares de participação do público de cinema, evitando a padronização do processo. Isso permite a criação de diferentes comunidades virtuais de acordo com a adaptação ao modo de interação.

Essas mudanças, no contexto de consumo de filmes nos festivais online durante a pandemia do Covid-19, radicalizaram a experiência do cinema e projetam transformações para o setor para as próximas décadas. Um dos aspectos que mais ganharam relevância diz respeito aos impactos do formato online na curadoria, programação e exibição dos filmes. Alpendre (2020) aponta que as mudanças vão possibilitar maior independência para curadores, mais acesso para o público, e visibilidade para artistas e profissionais do audiovisual. Dentre os pontos colocados pelo autor, destacamos dois que dialogam com a discussão colocada a respeito de engajamento e da participação na construção coletiva de sentidos na cibercultura. $O$ primeiro é sobre a acessibilidade. Uma pessoa que nunca participou de um festival de cinema pode participar de um evento sem sair de casa e ter acesso a filmes que dificilmente seriam disponibilizados de outra forma. O segundo ponto é sobre a opção dos festivais se tornarem híbridos, em que há a oferta dos filmes online, mas também há sessões presenciais. Essa última colocação é muito pertinente para o debate sobre a reinvenção dos festivais e o seu papel sociocultural na formação de plateia, no fomento 
à produção audiovisual independente, e no lugar de capacitação para o fazer e o pensar cinema no Brasil. Frente aos incontáveis conteúdos disponibilizados online, há um espaço a ser ocupado pelos curadores e idealizadores de festivais de cinema, que é o de conectar a audiência aos filmes, que antes estariam restritos a um certo grupo de entusiastas, cinéfilos, estudantes e profissionais.

No Brasil, como argumentamos ao longo do artigo, os festivais são também expressão de resistências e práticas sociais, principalmente para os festivais que tratam de temáticas sociais, étnicas e/ou raciais, socioambientais. A ampliação da visibilidade desses festivais com a potência gerada pela migração para o online agrega possibilidades de desenvolvimento do repertório audiovisual para levar esses temas a um público mais abrangente.

\section{CONCLUSÃO}

O esforço realizado pelos diretores(as) de festivais de cinema para a adaptação a um sistema online desvela a preocupação com o mercado audiovisual bastante impactado com a pandemia e revela várias tentativas e formatos testados que servirão de base para aperfeiçoamento da experiência. A permanência dos festivais tem um sentido de ocupação de espaços sociais politicamente disputados e é um ato de resistência e defesa da Cultura Nacional e dos espaços de expressão artísticos. Dessa forma, ao apresentamos os dados do questionário, complementados por dados contextuais do cenário audiovisual no Brasil, procuramos identificar e descrever fatores e processos que possam ser abarcados nos novos editais de financiamento de festivais, bem como informar agentes do mercado sobre novos indicadores a serem construídos a partir do que foi trazido neste artigo. As respostas constituíram base das análises a respeito das adaptações feitas para a realização dos festivais no formato online, bem como um diagnóstico sobre os resultados e principais aprendizados desse processo. Além disso, a pesquisa sobre o setor considerou os aspectos de consumo e distribuição, o da participação do público, as plataformas utilizadas para exibição dos filmes, as dificuldades na migração do presencial para o virtual, e as estratégias de comunicação.

Para tratar especialmente do segmento dos festivais de cinema no Brasil, realizados no formato digital, foi preciso compreender algumas condições e características desse setor cultural, a sua importância e o papel dos festivais no contexto da pandemia. O esforço da migração dos festivais para o online foi uma das formas de manter o mercado audiovisual aquecido, com circulação de novos produtos e abertura para novos agentes. Demonstrou a importância da classe artística na atuação em um contexto de crise, revelando a capacidade de mobilização e engajamento social e digital 
do setor audiovisual no Brasil. A pesquisa exploratória indica a necessidade de aprofundamento na análise desses dados e a ampliação com mais respondentes para uma representatividade maior dos achados.

\section{REFERÊNCIAS BIBLIOGRÁFICAS:}

ALMEIDA, Marco Antonio de. "Fluxos rizomáticos: potencialidades e limites para a circulação, apropriação e criação cultural". Texto Digital, v. 16, n. 1, jan./jul. 2020, p. 3654. Disponível em: https://doi.org/10.5007/1807-9288.2020v16n1p36. Acesso em: 27 de setembro de 2020 .

ALPENDRE, Sérgio. "Formato on-line traz chance de festivais de cinema serem mais ousados e independentes". Folha de S. Paulo, 29 ago. 2020. Disponível em: https://www1.folha.uol.com.br/ilustrissima/2020/08/formato-on-line-traz-chance-defestivais-de-cinema-serem-mais-ousados-e-independentes.shtml. Acesso: 2 de novembro de 2021.

ANCINE. Mapa de Mostras e Festivais 2020. Disponível em: https://www.ancine.gov.br/pt-br/mapa-de-mostras-e-festivais. Acesso em: 27 de setembro de 2020.

ANDRES, F. da C.; ANDRES , S. C.; MORESCHI, C.; RODRIGUES, S. O.; FERST, M. $F$. The use of the Google Forms platform in academic research: Experience report. Research, Society and Development, [S. I.], v. 9, n. 9, p. e284997174, 2020. DOI: 10.33448/rsd-v9i9.7174. Disponível em: https://rsdjournal.org/index.php/rsd/article/view/7174. Acesso em: 19 jan. 2022.

ARAUJO, E. S. de. "Lisboa como palco de Artivismo e Política". NAVA - Revista do Programa de Pós-Graduação em Artes, Cultura e Linguagens, Instituto de Artes e Design: UFJF, v. 2, n. 2, fev.-jul. 2017, p. 354-375. Disponível em: https://periodicos.ufjf.br/index.php/nava/article/view/28091. Acesso em: 4 de setembro de 2020.

ARAUJO, E. S. de; GALLO, P. R. "Etnocinema, Juventudes e Saúde Pública: a prática social do cinema e a abordagem interdisciplinar na pesquisa". GIS - Gesto, Imagem e Som - Revista de Antropologia, [S. I.], v. 2, n. 1, 2017, p. 2525-3123. Disponível em: http://www.revistas.usp.br/gis/article/view/129133. Acesso em: 27 de setembro de 2020.

AZEVEDO, Fábio Palácio de. "O Conceito de Cultura em Raymond Williams". Revista Interdisciplinar em Cultura e Sociedade, v. 3, n. especial, jul./dez. 2017. Disponível em: http://www.periodicoseletronicos.ufma.br/index.php/ricultsociedade/article/view/7755.

Acesso em: 27 de setembro de 2020.

BALAKHONSKAYA, L. V.; BALAKHONSKAYA, V. V. L. V. Balakhonskaya and V. V. Balakhonsky, "Pitching as a Communication Technology and Pitch as a Tool for Investor Relations in the Digital Environment," 2021 Communication Strategies in Digital Society Seminar (ComSDS), 2021, pp. 166-172. Disponível em: doi: 10.1109/ComSDS52473.2021.9422852. Acesso em 19 jan. 2022.

BENAKOUCHE, T. "Tecnologia é sociedade: contra a noção de impacto tecnológico". Caderno de Pesquisa, n. 17, Florianópolis: PPGSP/UFSC, set. 1999, p. 1-28. Disponível 
em: http://www.geocities.ws/ecdemoraes/texto tamara.pdf. Acesso em: 27 de setembro de 2020 .

CANCLINI, Néstor García. Culturas híbridas: estratégias para entrar e sair da modernidade. Trad. Heloísa P. Cintrão e Ana Regina Lessa. 2.ed. São Paulo: Edusp, 1998.

CERTEAU, Michel de. A invenção do cotidiano: artes de fazer. Petrópolis: Vozes, 1994.

CIRINO, N. N.; CANUTO, K. J. "Festivais de cinema pós-Covid-19: impactos e perspectivas". Significação: Revista de Cultura Audiovisual, [S. I.], v. 48, n. 56, 2021, p. 268-284. DOI: 10.11606/issn.2316-7114.sig.2021.176299. Disponível em: https://www.revistas.usp.br/significacao/article/view/176299. Acesso em: 8 de novembro de 2021.

CORREA, Paulo Luz (Org.). Guia Kinoforum de Festivais Audiovisuais 2019. São Paulo: Associação Kinoforum, 2020. Disponível em: http://www.kinoforum.org.br/guia/panorama-do-audio-visual-apresentacao. Acesso em: 27 de setembro de 2020.

DENNISON, S. Remapping Brazilian film culture in the twenty-first century. Londres: Routledge, 2019.

GARRETT, Adriano R. "A falta que faz: as particularidades do CachoeiraDoc dentro da nova configuração de festivais brasileiros". In: CESAR, A. et. al. (Orgs.). Desaguar em cinema: documentário, memória e ação com o CachoeiraDoc. Salvador: EDUFBA, 2020.

JENKINS, Henry. Cultura da Convergência. São Paulo: Aleph, 2008.

JENKINS, Henry; GREEN, Joshua; FORD, Sam. Cultura da Conexão: criando valor e significado por meio da mídia propagável. São Paulo: Editora ALEPH, 2014.

LEAL, Antonio; MATTOS, Tete (Org.). "Festivais audiovisuais: diagnostico setorial 2007: indicadores 2006". Fórum dos Festivais, 2007. Disponível em: https://www.cena.ufscar.br/wp-content/uploads/forum-dos-festivais-diagnostico20071.pdf. Acesso em: 24 de agosto de 2019.

LEMOS, André. "Epistemologia da comunicação, neomaterialismo e cultura digital". Galáxia, São Paulo, n. 43 abr. 2020, p. 54-66. Disponível em: http://www.scielo.br/scielo.php?script=sci arttext\&pid=S1982-

25532020000100054\&lng=en\&nrm=iso. Acesso em: 27 de setembro de 2020.

MACHADO PAIS, José. Lufa-lufa Quotidiana: ensaios sobre cidade, cultura e vida urbana. Lisboa: ICS, 2010.

MAGER, Juliana Muylaert. "A Contribuição do Festival É Tudo Verdade ao Cânone do Documentário Brasileiro". Aniki - Revista Portuguesa da Imagem em Movimento, v. 8, n. $1,2021,219-244$ p. Disponível em: https://aim.org.pt/ojs/index.php/revista/article/view/718. Acesso em: 13 de dezembro de 2021.

MALDONADO, A. E. "Transformação tecnocultural, cidadania e confluências metodológicas". In: Anais do XXXI Congresso Brasileiro de Ciências da Comunicação. 
Natal, $2008 . \quad$ Disponível em: http://www.intercom.org.br/papers/nacionais/2008/resumos/R3-0481-1.pdf. Acesso em: 27 de setembro de 2020.

MANOVICH, L. The language of new media. Massachusetts: The MIT Press, 2011.

MAPEAMENTO da Indústria Criativa no Brasil. Rio de Janeiro: Firjan-Senai, 2019. Disponível em: https://www.firian.com.br/EconomiaCriativa/downloads/MapeamentolndustriaCriativa.p df. Acesso em: 27 de setembro de 2020.

MARTINO, Luís Mauro Sá. Teoria das Mídias Digitais: linguagens, ambientes, redes. Petrópolis, RJ: Vozes, 2014.

MATTOS, Tetê. "Festivais pra quê? Um estudo crítico sobre festivais audiovisuais brasileiros". In: Mohamed Bamba (Org.). A Recepção Cinematográfica: teoria e estudos de casos. Salvador: EDUFBA, 2013, p. 115-130. Disponível em: https://www.academia.edu/27691073/Festivais pra qu\%C3\%AA Um estudo cr\%C3 \%Adtico sobre festivais audiovisuais brasileiros. Acesso em: 27 de setembro de 2020.

MATTOS, Tetê; LEAL, Antonio. "Festivais audiovisuais brasileiros: um diagnóstico do setor". In: V ENECULT, UFBA, maio 2009, Salvador. Disponível em: http://www.cult.ufba.br/enecult2009/19077.pdf. Acesso em: 27 de setembro de 2020.

NAYAR, Pramond Kuldip. An introduction to new media and cybercultures. Londres: Wiley-Blackwell, 2010.

NOLASCO, Igor. "Festivais e cineclubes virtuais: o cinema a um clique de distância". Revista Badaro, 32 set. 2020.2 Disponível em: https://revistabadaro.com.br/2020/09/03/festivais-cineclubes-virtuais/. Acesso em: 27 de setembro de 2020.

PRIMO, Alex. "Interações mediadas e remediadas: controvérsias entre as utopias da cibercultura e a grande indústria midiática". In: PRIMO, Alex. Interações em Rede. Porto Alegre: Sulina, 2013, p.13-32. Disponível em: https://www.academia.edu/12731813/Intera\%C3\%A7\%C3\%B5es mediadas e remedi adas controvC3\%A9rsias entre as utopias da cibercultura e a grande ind $\% \mathrm{C} 3 \% \mathrm{~B}$ Astria midi\%C3\%A1tica. Acesso em: 27 de setembro de 2020.

PROULX, Serge. "Trajetórias de uso das tecnologias de comunicação: as formas de apropriação da cultura digital como desafios de uma 'sociedade do conhecimento'". Trab. linguist. Aplic., Campinas, v. 49, n. 2, jul./dez. 2010, p. 443-453. Disponível em: http://www.scielo.br/scielo.php?script=sci arttext\&pid=S0103-

18132010000200008\&lng=en\&nrm=iso. Acesso em: 27 de setembro de 2020.

RECUERO, R. C. "Comunidades virtuais: uma abordagem teórica". In: Seminário Internacional de Comunicação, 2001, Porto Alegre. Anais eletrônicos. Porto Alegre: PUCRS, 2001. Disponível em: http://www.anpad.org.br/diversos/down zips/33/ADIA1697.pdf. Acesso em: 27 de setembro de 2020.

RESTEPRO, Eduardo. "Sobre os Estudos Culturais na América Latina”. Educação, Porto Alegre, v. 38, n. 1, jan-abr. 2015, p. 21-31. Disponível em: 
https://revistaseletronicas.pucrs.br/ojs/index.php/faced/article/view/20325/12750. Acesso em: 20 de setembro de 2020.

ROCHA, Adriano. M.; VACCARINI, Emmanuelle D. "A difusão do cinema brasileiro e o Cine Festival Inconfidentes: o audiovisual verde amarelo conquistando o interior de Minas Gerais". Experiência, Santa Maria, UFSM, v. 1, n. 1, jan.-jul. 2015, p. 3-19.

SANTAELLA, Lúcia. A ecologia pluralista da comunicação, mobilidade, ubiquidade. São Paulo: Paulus, 2010.

SOUSA, Ana Paula: "Corona Vírus vai marcar o fim de uma era no cinema". Folha de $S$. Paulo, 1 10 mai. 2020 . Disponível em: https://www1.folha.uol.com.br/ilustrissima/2020/05/coronavirus-vai-marcar-o-fim-deuma-era-nocinema.shtml?utm source=twitter\&utm medium=social\&utm campaign=twfolha. Acesso em: 27 de setembro de 2020.

HOW the creative economy can help power development. UNCTAD, 8 de nov. 2019. Disponível em: https://unctad.org/news/how-creative-economy-can-help-powerdevelopment. Acesso em: 27 de setembro de 2020.

WILLIAMS, Raymond. Cultura e sociedade: de Coleridge a Orwell. Petrópolis: Vozes, 2011.

\section{Anexo l:}

Formulário aplicado:

https://docs.google.com/forms/d/1t0Gg3XqlemOYDIBIn2LSd6CaZjiKFhxzJK3SCFxKOx M/edit\#responses 